\title{
O Retorno do Fundamento à Identidade: O Fechamento do Sistema Hegeliano
}

The Return from Foundation to Identity: The Closure of the Hegelian System

\author{
Michele Borges Heldt \\ (Universidade do Vale do Rio dos Sinos, Brasil)
}

\section{Resumo}

Na Doutrina da Essência, que é o segundo livro da Ciência da Lógica, Hegel desenvolve a estrutura das determinações de reflexão (Reflexionsbestimmungen). Essa estrutu$\mathrm{ra}$, enquanto proposta de mediação pura, deve formar um sistema lógico fechado, que equivale, em termos hegelia-nos, ao retorno do fundamento para a identidade. Neste artigo buscar-se-á analisar este movimento, bem como alguns pormenores argumentativos e conceitos que tal análise, necessariamente, implica.

Palavra-chave: Identidade. Fundamento. Diversidade. Contradição. Diferença.

\begin{abstract}
In the Doctrine of Essence, which is the second book in the Science of Logic, Hegel develops the structure of the reflections determinations (Reflexions-bestimmungen). This structure, as a proposal for pure mediation, must form a closed logical system, which is equivalent, in Hegelian terms, to the return of the foundation for identity. This article will seek to analyze this movement, as well as some argumentative details and concepts that such analysis necessarily implies.
\end{abstract}

Keywords: Identity. Difference. Diversity. Contradiction. Foundation. 


\section{Introdução}

$\mathrm{Na}$ estrutura das determinações de reflexão Hegel articula as seguintes progressões categoriais: 1) identidade para diferença absoluta; 2) diferença absoluta para diversidade; 3) diversidade para oposição; 4) oposição para contradição; e 5) contradição para o fundamento. Segundo Wölfle, nestas progressões o que predomina é o imediatismo da mediação pura, "[...] o não ser da reflexão, através do qual a essência se media"1.

Enquanto mediações puras, as determinações da reflexão, conforme mencionado, devem formar um sistema lógico fechado, o que significa que a categoria fundamento deve retornar à categoria inicial, a identidade. No entanto, o termo "fundamento" (Grund), sofre de uma ambiguidade, posto que pode ser traduzido tanto por fundamento, no sentido de base para algo, como no sentido de motivo pelo qual algo vem a ser. Assim, haverá que se entender em que medida essa ambiguidade integra essencialmente o conteúdo da categoria "Grund", ou se é somente um problema linguístico exterior à determinação pura do pensar.

\section{A Ambiguidade do termo Grund}

Existe uma linha interpretativa que aqui nos interessa: uma razão (Grund) que ainda não se pensou a si mesma, em face de uma razão (Abgrund) que, confrontada com algo outro pelo qual ela se determina, percebe, todavia, que nunca o alcançará.

$\mathrm{Na}$ perspectiva da razão finita, que não empreendeu ainda o seu processo de determinação de si, o que a caracterizaria enquanto razão infinita,

\footnotetext{
1 "[...] das Nichtsein der Reflexion, durch das Wesen sich vermittelt". (WÖLFLE, 1994, p. 244).
} 
uma razão ainda confrontada com um outro que a supera e ultrapassa [...]. Um outro que se mantém sempre para além dela, constituindo uma espécie de Abismo (Abgrund), diante do qual ela recua. (ROSENFIELD, 2018, p. 48).

Neste ponto ainda não há mediação, mas, como diz Rosenfield "uma parada frente a algo intransponível", (2018, p. 49), e isso explica, como será visto mais adiante, a introdução da categoria "nada" logo no início da lógica hegeliana.

Entretanto, ainda segundo Rosenfield (2018, p. 49):

O empreendimento hegeliano, porém, consistirá em fazer deste "Abgrund" um "Grund", do "abismo" um "fundamento", do imediato uma etapa da mediação, mediante a qual o ser puro chega a si mesmo, o Absoluto apresentando-se enquanto condição e resultado deste processo de mediação. O Abgrund enquanto fundamento negativo tornar-se-á a essência apresentando-se como mediação do ser, a essência engendrando-se em sua reflexão, em sua negatividade, como fundamento positivo. O Abgrund aparece, então, verdadeiramente enquanto momento do Grund.

Quando Rosenfield diz que Hegel almeja fazer do abismo um fundamento, ele quer dizer que Hegel busca expor a negatividade imanente que envolve pensar o fundamento como algo originário: ora, o fundamento, quando determinado, já está sendo, portanto, não provém de algo outro se não dele mesmo. É justamente por isso que a lógica hegeliana se inicia pelo ser, porque o puro pensar não se refere a algo que precede o ser, mas a algo que se dá através do ser independentemente de qualquer outra coisa. Assim, é puro porque o método e o objeto, em 
última análise, são um só. As determinações de reflexão que, segundo a análise hegeliana, são as determinações categoriais que fundamentam o pensar dos objetos representados como reais, somente se desenvolvem dentro do próprio pensar.

Neste sentido, Grund como Abgrund é uma analogia que Rosenfield utiliza para dizer que, do mesmo modo como não é possível enxergar o fim de um abismo, mas apenas chegar à beira deste, também não é possível determinar o fundamento como algo estanque, algo que possa se dizer "aqui é o começo", posto que este começo, todavia, já está sendo.

Tudo o que é pensado e expresso, somente o é por meio de determinações. Essa necessidade de determinação constitui uma contradição para Hegel. Entrementes, é dessa forma que as coisas vêm a ser. Portanto, é a partir dessa necessidade que a identidade, onde a negação é igual à negação, se estabelece. É justamente esse movimento de realização em algo outro a suprassunção da contradição em termos hegelianos que Hegel vai buscar demonstrar, através de seu método dialético, como sendo o fundamento, ou seja, um movimento que se apresenta como ser posto (imediato), bem como o motivo (mediado) de sua existência.

De acordo com Wölfle, "as determinações de reflexão estão na relação de uma mediação pura (...) porque os seus momentos ainda não estão configurados para a independência" ${ }^{2}$, ao passo que o fundamento "é a mediação real, porque nela se alcança a independência e a

2 “Die Reflexionsbestimmungen im Verhältnis einer reinen Vermittlung (...) weil ihre Beziehung und ihre Momente noch nicht zur Selbständigkeit ausgebildet sind". (WÖLFLE, 1994, p. 244). 
imediatez dos momentos" ${ }^{\prime 3}$. Ocorre, porém, que o fundamento, enquanto categoria, ainda faz parte da estrutura das determinações de reflexão que Wölfle afirma que estão em mediação pura. Logo, como pode o fundamento ser mediação real?

Porém, Wölfle insiste que o fundamento, no sentido de mediação real, encontra-se em um nível superior em relação às demais determinações, e com isso assume "(...) a estrutura lógica de ligação do ser no nível de estágios"4. Na sequência do texto, contudo, percebe-se que Wölfle diferencia motivo de fundamento: toda vez que se refere à mediação real, utiliza o termo fundamento, ao passo que, ao referir-se à mediação pura, emprega o termo motivo. Disso se pode inferir que, para Wölfle, o termo Grund, traduzido por motivo, representa a última categoria da estrutura das determinações de reflexão enquanto mediação pura, ao passo que Grund, traduzido por fundamento, estabelece um outro tipo de mediação, com o real ${ }^{5}$.

Mas o que tem essa categoria de diferente das demais para que tal diferenciação ocorra? De início, o que se sabe é que em Grund a sobreposição de níveis de todas as categorias anteriores - integrantes da estrutura das determinações de reflexão - se completa, e isso é o que há

3 "Der Grund, die reale Vermittlung dar, weil in inm die Selbständigkeit und Unmittelbarkeit der Momente erreicht ist" (WÖLFLE, 1994, p. 244). 4 "(...) die logische Verbindungsstruktur, auf Stufe zu sein". (WÖLFLE, 1994, p. 244).

${ }^{5}$ Em Hegel, existe uma diferença entre o efetivo (Wirklich) e o real (Reell). O ser é o efetivo que pode ou não se concretizar no real. Dessa forma, talvez aqui o termo mais apropriado fosse o efetivo ao invés de real, uma vez que se está a falar da esfera lógica. No entanto, Wölfle utiliza o termo "real".

174 • Ágora Filosófica, Recife, v. 21, n. 1, p. 170-197, jan./abr., 2021 
de diferente nesta categoria em relação às imediatamente anteriores. Provavelmente é neste sentido que Wölfle afirma que o motivo é a "(...) essência em si mesma como fundamento" ${ }^{\prime \prime}$, ao passo que, enquanto categoria lógica, sua determinação enquanto fundamento é formal.

Além disso, há que se observar também a progressão categorial anterior, isto é, a progressão da contradição ao fundamento. Segundo Hegel, "a contradição resolvida é o fundamento, a essência como unidade do positivo e do negativo" ${ }^{7}$. O ser que somente vem a ser por meio de algo outro, a sua determinação, e que, assim sendo, converte-se imediatamente neste outro, suprassumindo-o, é o que Hegel chamou de Aufhebung, o movimento de superação da contradição imanente. Sob este prisma, o fundamento, justamente por expressar em si este movimento, é a própria essência, isto é, um fundamento auto-movente. Assim, o fundamento, em Hegel, possui dois sentidos: enquanto categoria lógica representa a mediação real, ao passo que, enquanto motivo, é mediação pura.

\section{Retorno do Fundamento à Identidade}

De acordo com Hegel, "(...) em si, a essência retorna como essência que nega; em seu retorno a si, portanto, há uma determinidade em si mesma, que por isso mesmo é o negativo que é idêntico a si, o ser-posto suprassumido que, portanto, é tanto negativo quanto identidade" ${ }^{\prime 8}$. Ou

\footnotetext{
6 “(...) des Wesens mit sich als Grund ist". (WÖLFLE, 1994, p. 244).

7 "Der aufgelöste Widerspruch ist also der Grund, das Wesen als Einheit des Positive und Negative" . (HEGEL, 1969, p. 282)

8 "In sich kehrt das Wesen zurück als negierendes; es gibt sich also in seiner Rückkehr in sich die Bestimmtheit, die eben darum das mit sich identische Negative, das aufgehobene Gesetztsein, und somit Ágora Filosófica, Recife, v. 21, n. 1, p. 170-197, jan./abr., $2021 \cdot 175$
} 
seja, na progressão categorial do fundamento para a identidade, ao mesmo tempo em que ocorre o movimento de fechamento deste sistema lógico, ocorre também que a determinação da essência acarreta na negação do que ela é em si mesma, mediação pura, o que acaba por forçar uma nova progressão.

Nesse sentido, seria possível afirmar que a progressão da essência ao fundamento, ao mesmo tempo em que retorna para a identidade, acaba também por causar uma outra progressão categorial? Afinal, este é o procedimento típico da dialética: cada ciclo encerra-se e abre caminho para uma nova progressão. Contudo, é preciso compreender como este movimento ocorre.

Ao retornar para a identidade, a essência se efetiva por meio daquilo que ela não é. $E$, efetivando-se por meio de seu não-ser, a essência se mostra idêntica àquilo que ela é, qual seja, um abstrato indeterminado. Nas palavras de Hegel

(...) é a identidade consigo mesma, que é a essência como a subsistência da determinação; é a contradição de ser suprassumida no seu ser-posto, e de ter a subsistência nesse ser-suprassumido, assim, o fundamento como a essência idêntica a si no ser-negado ou determinado. ${ }^{9}$.

Dessa forma, o retorno do fundamento para a identidade causaria também a progressão da essência (denominada agora fundamento) ao ser, que é um novo

ebensosehr seiendes als die Identität". (HEGEL, 1969, p. 64).

9 “(...) ist die Identität mit sich, welche das Wesen als das Bestehen der Bestimmung ist; sie ist der Widerspruch, in ihrem Gesetztsein aufgehoben zu sein und an diesem Aufgehobensein das Bestehen zu haben, - somit der Grund als das im Bestimmt- oder Negiertsein mit sich identische Wesen". (HEGEL, 1969, p. 69).

176 • Ágora Filosófica, Recife, v. 21, n. 1, p. 170-197, jan./abr., 2021 
ciclo lógico. Logo, o que se teria aqui não seria o fechamento total do sistema, mas sim um movimento em espiral, onde a última categoria não segue o mesmo padrão lógico das demais. Ciente deste desdobramento, Hegel então denomina esta categoria como "Grund", que pode ser tanto motivo, o qual retorna para a identidade, quanto fundamento que progride ao ser, agora restaurado como "mediação real".

Supondo que este argumento esteja correto, o que ocorreria na progressão categorial do fundamento ao ser, isto é, de um ciclo lógico completo a outro?

Ora, na categoria ser o que se encontra, logo de início, é a dialética de ser e nada, que é, justamente, o início da lógica do ser. Certamente essa dialética não se desenvolve ali à toa, e a pergunta providencial que se deve fazer neste ponto é: porque Hegel desenvolve a dialética de ser e nada ao invés da dialética de ser e não-ser? Se o ser se concretiza em seu não-ser, retornando, dessa forma, a si, o que a categoria nada está fazendo ali?

Para Wandschneider, "obviamente não-ser não pode ser substituído pelo nada"10, posto que são duas categorias diferentes. Ocorre que, em Hegel, tudo tem um sentido, e o nada, justamente no início da lógica do ser, tem a função de sinalizar que, nesta progressão categorial, não existe nada além disso. Ora, o nada já está sendo,

(...) e, portanto, [é] já ser-determinado ${ }^{11}$. Assim, a progressão do ser ao nada significa, na verdade, a progressão do ser ao ser, todavia, se Hegel tivesse desenvolvido a dialética de ser e não-ser, este

10 "Nichtsein entsprechend kann aber offenbar nicht durch Nichts entsprechend ". (WANDSCHNEIDER, 1997, p. 142).

11 "(...) und damit also schon bestimmtes Sein". (WANDSCHNEIDER, 1997, p. 141).

Ágora Filosófica, Recife, v. 21, n. 1, p. 170-197, jan./abr., $2021 \cdot 177$ 
poderia ser interpretado como o não-ser de outras coisas também determinadas, o que não é o caso. “Um ser pode, de fato, como afirmado, ser um certo ser e ao mesmo tempo ser um não-ser, isto é, um não ser de outro ser definido; mas não pode ser nada ao mesmo tempo ${ }^{12}$.

Dessa forma, o nada precisamente inserido no início da lógica do ser, tem por finalidade demonstrar a unidade indissolúvel com o ser. Como diz Wandschneider "está presente uma unidade com o $\operatorname{ser}^{13}$ e todas as categorias da lógica hegeliana estão, desde o princípio, nessa unidade ${ }^{14}$, inclusive a categoria fundamento. Disso se pode concluir que não existe progressão categorial do fundamento ao ser, dado que este já está sendo, portanto, o ser encontra-se, desde o princípio, posto. O que existe é a diferença entre uma conexão lógica que se dá de modo necessário, e a posterior introdução da reflexão acerca destas conexões.

Não-ser é então usado predicativamente no sentido de um não-ser de alguma coisa. Por outro lado, se perante o ser estivesse [0] "nada" então haveria apenas ser, sem quaisquer continuações. com a categoria [do] nada, o processo de progressão dialética seria interrompido e lançado de volta ao

12 "Ein Sein kann zwar, wie dargelegt, als ein bestimmtes Sein zugleich ein Nichtsein sein, nämlich Nichtsein von anderem bestimmten Sein; aber es kann nicht zugleich nichts sein“. (WANDSCHNEIDER, 1997, p. 142).

13 "(...) ist eine Einheit mit dem Sein vorhanden". (WANDSCHNEIDER, 1997, p. 141).

14 Neste caso, a lógica da essência deve ser compreendida como um subsistema dentro da lógica do ser que, por sua vez, é um subsistema dentro da grande lógica do conceito, de onde tudo é derivado.

178 • Ágora Filosófica, Recife, v. 21, n. 1, p. 170-197, jan./abr., 2021 
começo. Nada seria a negação absoluta de novos aspectos possíveis ${ }^{15}$.

Nesse contexto, não existe progressão da categoria fundamento para a categoria ser, mas tão somente o retorno da categoria fundamento para a categoria identidade, dado que, em se tratando de mediação pura, o sistema lógico das determinações de reflexão precisa ser fechado. Assim sendo, o presente artigo deve focar-se, daqui para diante, na análise desta última progressão.

Entretanto, quando Hegel fala de identidade, há de se ressaltar que não se está referindo apenas à imediatez da identidade lógica, mas a "igualdade consigo mesma, que é estabelecida com a unidade, não uma restauração de outra, mas essa pura instauração a partir de si mesma, a identidade essencial"16. A identidade essencial a qual Hegel se refere é a identidade estabelecida a partir da unidade onde os opostos se alternam e se convertem imediatamente um no outro, formando, desse modo, uma unidade identitária que reflete a essência daquilo que se está conhecendo por meio das determinações de reflexão. É a identidade lógica pensada a partir da metodologia

15 "Nichtsein ist dann prädikativ verwendet im Sinn eines Nichtseins von etwas. Stünde hingegen dem Sein 'nichts' gegenüber. so gäbe es eben nur Sein, ohne alle Weiterungen. Mit der Kategorie Nichts wäre der Prozeß dialektischer Fortbestimmung abgeschnitten und auf den Anfang zurückgeworfen. Nichts wäre die absolute Negation möglicher neuer Hinsichten“. (WANDSCHNEIDER, 1997, p. 142).

16 "Diese Identität mit sich ist die Unmittelbarkeit der Reflexion. Sie ist nicht diejenige Gleichheit mit sich, welche das Sein oder auch das Nichts ist, sondern die Gleichheit mit sich, welche als sich zur Einheit herstellende ist, nicht ein Wiederherstellen aus einem Andern, sondern dies reine Herstellen aus und in sich selbst, die wesentliche Identität". (HEGEL, 1969, p. 26).

Ágora Filosófica, Recife, v. 21, n. 1, p. 170-197, jan./abr., $2021 \cdot 179$ 
hegeliana que, justamente por isso, já não se refere mais apenas à imediatez da identidade lógica.

Ao ser expresso por meio de uma identidade determinada, o fundamento já está sendo, portanto, este já veio a ser, e com isso a diferença, bem como a oposição já foram superadas e, consequentemente, também a contradição. Esse movimento de suprassunção, o qual Hegel denominou Aufhebung, significa que, toda vez que algo "é" algo - posto na identidade, portanto - tal movimento sempre já ocorreu.

Ao retornar para a identidade, o fundamento, enquanto "é", já superou a oposição de ser expresso por meio de algo outro, o que, consequentemente, suspende as demais determinações de reflexão, integrando, portanto, todas elas em uma única categoria. Como diz Flach, “(...) não mais como membro da série dos elementos presentes, mas apenas como momentos que têm a sua unidade nele"17. É por isso que Hegel afirma que o fundamento é a identidade da essência, não apenas identidade simples, mas é este fundamento auto-movente que se funda a si mesmo e, quando entra na identidade, suspende todas as demais determinações.

A determinação de reflexão, na medida em que regressa para dentro do fundamento, é um ser aí primeiro, um ser aí imediato em geral, do qual se inicia. Mas, o ser aí tem ainda somente o significado do ser posto e pressupõe essencialmente um fundamento, - no sentido de que ele, antes, não o põe, que este pôr é um suprassumir de si mesmo, o imediato, antes, é o posto, e o fundamento é o não

17 “(...) nicht mehr als Mitglied der Reihe der vorhandenen Elemente, sondern nur als Momente, die ihre Einheit darin haben“. (FLACH, 1959, p. 48-49).

180 • Ágora Filosófica, Recife, v. 21, n. 1, p. 170-197, jan./abr., 2021 
posto. Como resultou, este pressupor é o pôr, o qual se repercute sobre o ponente. (HEGEL, 2017, p. 147).

Em última análise, o fundamento é o pensamento que se autodetermina para poder ser pensado. Em Hegel, a origem do pensamento está na ideia absoluta, uma vez que tudo o que vem a ser se dá, justamente, no âmbito da ideia. Todavia, de acordo com as explicações de Flach (1959, p. 40-48), todo pensamento também inclui "forma e conteúdo", o que significa que, no exercício do pensamento, ele entra no regime de heterogeneidade. Nesse ínterim, o princípio da não-contradição é o operador lógico que tem por finalidade restituir a homogeneidade do pensamento e, dessa forma, recuperar a sua característica mais fundamental.

\section{Papel Metodológico da Contrdição como Fator Gerador de Sistema}

De acordo com Flach (1959, p. 79-80), a negação (da determinação) aparece apenas no juízo, que não é o princípio do pensamento (que já ocorreu), mas apenas o lugar onde ele é exercido. Nesse contexto, o movimento de suprassunção da contradição é o princípio do pensamento, o qual, posteriormente, gera o juízo. Assim, "a contradição resolvida é o fundamento como unidade do positivo e do negativo". ${ }^{18} \mathrm{Ou}$, em outras palavras, a contradição resolvida é o fundamento no sentido de que restitui a homogeneidade do pensamento em sua essência.

Quando Flach fala de homogeneidade e

\footnotetext{
18 "Der gelöste Widerspruch ist der Grund, als Einheit des Positiven und Negativen". (HEGEL, 1969, p. 282).
}

Ágora Filosófica, Recife, v. 21, n. 1, p. 170-197, jan./abr., $2021 \cdot 181$ 
heterogeneidade do pensamento, na verdade, ele está tocando em um ponto fulcral para o conceito de contradição em Hegel. Isso porque, segundo Horstmann, a metafísica "(...) baseia-se em uma interpretação equivocada do que Hegel chama 'a forma do juízo', e, consequentemente, do que um juízo tem a nos dizer sobre a realidade"19. De acordo com Horstmann, o princípio básico de um juízo, em Hegel, é a forma sujeitopredicado (que em seu fundamento é homogênea), contudo, "a metafísica tradicional está equivocada acerca do que significa a expressão sujeito no que se refere ao conteúdo"20.

Isso porque, para Hegel, diferentemente de Kant e da metafísica tradicional, é possível sim estabelecer uma identidade pelo movimento, isto é, a partir da relação entre o objeto e a sua determinação. Daí o entendimento de Hegel acerca da necessidade de um instrumento metodológico diferente da metafísica tradicional para o desenvolvimento de sua filosofia, sem que o mesmo precisasse renunciar à forma do juízo como princípio fundamental do discurso filosófico. Dessa forma, Hegel necessitava desenvolver um método filosófico alternativo para lidar com os juízos. É precisamente aqui que o conceito de contradição vem a desempenhar um papel metodológico, como fator gerador do sistema. E, novamente aqui, Hegel parte de Kant, ou melhor, de uma crítica à filosofia kantiana.

\footnotetext{
19 “(...) se basa en una interpretación equivocada de lo que Hegel llama "la forma del juicio", y, en consecuencia de lo qué tiene que decirnos un juicio sobre la realidade". (HORSTMANN, 2009, p. 194-195).

20 "(...) la metafísica tradicional está equivocada acerca de qué significa la expresión-sujeto en lo que se refiere al contenido". (HORSTMANN, 2009, p. 195).

182 • Ágora Filosófica, Recife, v. 21, n. 1, p. 170-197, jan./abr., 2021
} 
Em sua Crítica da Razão Pura Kant afirma que, quando um predicado é contraditório em relação ao seu objeto - como "bola quadrada", por exemplo -, o mesmo equivale a "nada", nihil negativum, no sentido de que não é possível encontrar uma representação adequada deste.

(...) Dado que tudo o que se pode afirmar ou negar deste objeto é falso, este objeto não tem conteúdo representacional, não é nada, não há modo possível de encontrar uma representação deste objeto. $E$ este resultado peculiar se deve ao fato de que cada predicado e sua negação contradizem o conceitosujeito ${ }^{21}$.

Provavelmente, é neste ponto que Hegel percebe que, se é justamente a relação contraditória entre o sujeito e o objeto a responsável pela ausência de conteúdo representacional, então se poderia pensar na contradição como "um instrumento metodológico cujo emprego permite romper a conexão entre o juízo e a representação" 22 e, desta forma, restituir a unidade entre sujeito e objeto. Em contrapartida, isso também não quer dizer que Hegel pretende se referir à verdade da coisa em si de maneira kantiana, mas, quando Hegel se refere ao objeto, o mesmo quer dizer "objeto da lógica" que, em última instância, refere-se ao conceito do objeto - o objeto é também o conceito e inversamente.

O conceito, para Hegel, possui um significado

21 “(...) dado que todo lo que se puede afirmar o negar de este objeto es falso, este objeto no tiene contenido representacional, no es nada, no hay modo posible de encontrar uma representación de este objeto. $Y$ este resultado peculiar se debe al hecho de que cada predicado y su negación contradicen al concepto-sujeto" (HORSTMANN, 2009, p. 198).

22 "un instrumento metodológico cuyo empleo permite romper la conexión entre juicio y representación" (HORSTMANN, 2009, p. 198).

Ágora Filosófica, Recife, v. 21, n. 1, p. 170-197, jan./abr., $2021 \cdot 183$ 
oposto do que para Kant, dado que, para este, o conceito é algo meramente representacional e que, portanto, nada tem a ver com a verdade da coisa em si, mas unicamente com a sua apreensão e síntese objetiva e empírica. Pressupor que o conceito se refere à verdade da coisa em si, para Kant, constitui uma antinomia, denominada antinomia da razão. Já para Hegel, porque pressupor a verdade da coisa em si constitui uma antinomia, o conceito é em si mesmo antinômico, uma vez que se converte imediatamente naquilo que o objeto "é".

A ideia de que o conceito pode não corresponder ao que o objeto é em si mesmo se desenvolve (ou não) apenas em um segundo momento, a partir da reflexão acerca deste primeiro saber.

De acordo com esse conceito, as contradições pertencem à própria natureza dos objetos, pelo menos na medida em que são tomados como realmente são. Porque se se pensa em objetos como complexos de Denkbestimmungen e se, como foi mencionado antes, as Denkbestimmungen são pensadas como algo cujo significado é fixado apenas pela integração de seu oposto (como necessariamente contraditório nesse sentido especial indicado) então o conceito de contradição é, por assim dizer, integrado (incorporado) no conceito de objeto. ${ }^{23}$

23 "De acuerdo a este concepto, las contradicciones pertenecen a la misma naturaleza de los objetos, al menos en la medida en que estos se tomen como realmente son. Porque si se piensa a los objetos como complejos de Denkbestimmungen y si, como fue mencionado antes, se piensa a las Denkbestimmungen como algo cuyo significado es fijado sólo al integrar su opuesto (como necesariamente contradictorio en aquel sentido especial señalado) entonces el concepto de contradicción está, por así decirlo, integrado (build in) en el concepto de objeto". (HORSTMANN, 2009, p. 205-206). 
Die Reflexionsbestimmungen - as determinações de reflexão - referem-se à estrutura desenvolvida por Hegel na Doutrina da Essência para tratar não apenas da contradição, mas também do modo como o pensamento lógico se desenvolve. As Reflexionsbestimmungen são um tipo de Denkbestimmungen que, por sua vez, são as determinações do pensamento (e disso se infere que a reflexão se dá através do pensar). Dentro dessa estrutura das determinações de reflexão, a contradição não é somente parte constitutiva, como também é a responsável pela progressão de uma categoria para outra.

\section{Uma Proposta de Atualização}

Sob a perspectiva de uma antinomia da razão, já que Hegel parte de Kant, a estrutura das determinações de reflexão, enquanto estrutura antinômica (dado que contém a contradição) pode ser expressa, ou melhor, pode ser reconstruída da seguinte forma: quando Mactaggart (1910, p. 104) fala de "superfície e substrato", o que ele quer dizer é que Hegel desenvolve a sua lógica da essência em unidade com a lógica do ser. E, ao passo que, na lógica do ser, a identidade se desenvolve a partir da igualdade, onde o ser é igual a ser, na lógica da essência a identidade, contrariamente, se desenvolve a partir da desigualdade. Isso ocorre porque a dialética que Hegel desenvolve para expor a lógica da essência mostra que a categoria "ser" somente se desenvolve em relação, mesmo que subjacente, com a categoria oposta "não-ser" (sua determinação), o que causa a primeira progressão categorial, de ser a nada, que é o não-ser.

O confrontamento destes dois termos opostos colocados agora em relação, produz, por sua vez, uma 
oposição semântica, isto é, uma oposição entre palavras com sentidos opostos. A oposição semântica é, portanto, a segunda etapa nessa reconstrução. Nessa etapa, conforme explica Wandschneider (1997, p. 125-131), ao confrontar os termos "ser e nada" percebe-se, no entanto, que um pressupõe sempre o outro: o ser passa para o nada que, determinado, passa para o ser.

Nesse sentido, o que se tem, neste ponto, é uma contradição dialético-pragmática, isto é, uma contradição que se dá a nível das propriedades das categorias lógicas, uma vez que cada categoria se constitui a partir da relação subjacente com a sua categoria oposta. Assim, a oposição semântica progride para a contradição dialéticopragmática, que é a terceira etapa desse sistema.

Por outro lado, a categoria nada, uma vez determinada, já veio a ser, portanto, em última análise, não se está referindo aqui à categoria em si, mas, antes, ao seu significado. Assim, o que se tem, neste ponto, é uma contradição dialético-semântica, isto é, uma contradição que se dá a nível de significado destas categorias, e não do que elas são em si. Ou, em outras palavras, é o conceito de "nada", uma vez que não é possível alcançar o que este é em si mesmo. Disso se pode inferir que, em Hegel, ser e significado são o mesmo, uma vez que não se pode supor nenhum outro ser que não seja o significado.

Ao deduzir tais categorias lógicas unicamente do conceito e não da experiência sensível (muito embora o conceito pressuponha a verdade da coisa em si e, justamente por isso, Hegel o considera antinômico), as operações hegelianas continuam, no entanto, atuando no campo da razão, do que se pode inferir que essa contradição oriunda da constante necessidade de referir- 
se sempre ao seu oposto pode ser compreendida como uma contradição lógica, exatamente do mesmo modo que as antinomias - as quais causam a imediata ambivalência entre funções opostas porque, em última análise, se referem a um conjunto de coisas - são trabalhadas na lógica formal. Dessa forma, a contradição dialéticosemântica e a contradição lógica constituem a quarta e a quinta etapa dessa atualização, respectivamente.

Por fim, mas não menos importante, o que se tem na próxima etapa é uma contradição que, quando constatada, já ocorreu e já foi superada. Isso ocorre porque, na dialética hegeliana, algo somente vem a ser por meio de algo outro, portanto, já de início, o que se tem é sempre uma oposição suprimida, o que, consequentemente, suspende também a contradição. Assim, a oposição superada constitui a sexta ${ }^{24}$ fase dessa reconstrução. Essa é a última etapa, porém ainda é preciso fechar o sistema, posto que Hegel desenvolve a sua dialética de modo circular. Dessa forma, nessa atualização é preciso, ainda, compreender como ocorre a progressão categorial da oposição superada para a identidade lógica, ou, em termos hegelianos, o retorno do fundamento para a identidade.

De acordo com os preceitos kantianos - e também da metafísica tradicional - a forma como o mundo é percebido não corresponde à verdade do que este é em si, daí a busca de Hegel por um movimento de superação constante da forma, denominado por ele de Aufhebung. Nesse sistema - chamo de sistema porque é a

24 1) identidade lógica; 2) oposição semântica; 3) contradição dialéticopragmática; 4) contradição dialético-semântica; 5) contradição lógica; 6) oposição superada. 
insuficiência de um momento que leva a outro, que por sua vez leva a outro, e assim sucessivamente - "a forma do enunciado a ser superada (Aufgehoben), não é algo que só tem que acontecer de modo imediato, (...) mas este movimento contraditório (Entgegengesetze) deve ser explicitado"25. Ainda segundo Horstmann, esse movimento “(...) é o movimento dialético do próprio enunciado. Só ele é realmente especulativo, (...) e apenas sua a explicitação é uma exposição dialética" ${ }^{26}$, do que se pode inferir que o pensamento metafísico tradicional é irrefletido, uma vez que baseia-se apenas na imediatez do entendimento, e não na reflexão acerca deste (esta é, a meu ver, a diferença fundamental entre a dialética hegeliana e a metafísica tradicional).

Já de acordo com a filosofia kantiana, mesmo tal reflexão ainda não passa de uma "ilusão da razão", sendo que o pensamento especulativo está, do mesmo modo, fadado ao erro, onde "tudo que é chamado de filosofia seria uma mera ilusão de uma suposta compreensão da verdade $^{\prime 27}$. Nesse contexto, o que resta ao pensamento especulativo é a busca pela constante correção do seu sistema filosófico (nesse sentido, diferentemente do anterior, não é um sistema fechado), tal como atua o método científico de tentativa e erro, daí a formulação

25 "Que la forma del enunciado sea superada (aufgehoben), no es algo que sólo tiene que suceder de modo inmediato, (...) sino que este movimiento contradictorio (entgegengesetze) debe explicitarse". (HORSTMANN, 2009, p. 200).

26 “(...) es el movimiento dialéctico del enunciado mismo. Sólo él es lo realmente especulativo y sólo la explicitación del mismo es <una> exposición dialéctica". (HORSTMANN, 2009, p. 200).

27 "Alles, was Philosophie heißt, auf einen bloßen Wahn von vermeinter Vernunfteinsicht hinauslaufen würde". (KULENKAMPFF, 1970, p. 100).

188 • Ágora Filosófica, Recife, v. 21, n. 1, p. 170-197, jan./abr., 2021 
hegeliana de uma Ciência da Lógica.

De acordo com Kulenkampff, o pensamento especulativo deve compreender a oposição “(...) no sentido de uma tarefa aberta, infinita, sempre mais distante ou sempre renovadora, para definir e determinar"28 ou, em outras palavras, deve ter sempre o espírito absoluto pressuposto, enquanto algo que simplesmente escapa ao entendimento. Assim, “(...) o absoluto se torna a relação especulativa antinômica de Hegel"29, no sentido de ser aquele pressuposto como verdadeiro que está, simultaneamente, a ser alcançado e já alcançado. Dessa forma, a "filosofia especulativa é o pensamento do absoluto no absoluto"30.

A reflexão acerca do saber e da intuição, que é o modo de acesso direto ao objeto da representação, pressupõe tempo, e esta é uma das principais críticas em relação à lógica hegeliana, dado que tempo é uma categoria da filosofia do real e não objeto da lógica tradicional. No entanto, conforme explica Kulenkampf, o método hegeliano apenas expõe o movimento intrínseco à intuição, e essa capacidade de junção de todos estes momentos em apenas um. "No intuir da intuição, portanto, tudo se torna como e em um, ou um idêntico a tudo. "31

28 “(...) in Gestalt des offen-endlosen Immer-noch-weiter oder der immerfort sich erneuernden Aufgabe zu setzen und zu bestimmen". (KULENKAMPFF, 1970, p. 100).

29 “(...) des Absoluten wird das antinomische spekulative Verhälmis von Hegel". (KULENKAMPFF, 1970, p. 100).

30 "Die spekulative Philosophie ist das Denken des Absoluten im Absoluten". (KULENKAMPFF, 1970, p. 100).

31 "Im Anschauen des Anschauens wird sonach Alles als und in Eines, beziehungsweise, Eines mit Allem identisdi". (KULENKAMPFF, 1970, p. 101).

Ágora Filosófica, Recife, v. 21, n. 1, p. 170-197, jan./abr., $2021 \cdot 189$ 
A exposição do movimento de formação do conhecimento em nada modifica a imediaticidade da categoria da identidade, mas apenas demonstra a "unidade de reflexividade e irreflexividade que a base da ciência, ou conhecimento em geral é"32, e não à toa que a estrutura das determinações de reflexão começa justamente pela categoria identidade. Essa identidade, porém, implicitamente contém uma contradição suprassumida, isto é, a recorrência a uma determinação externa que é imediatamente acatada como verdadeira, ou, em outras palavras, a contradição pressuposta pela identidade é a contradição contida na reflexão determinante. Dessa forma, todas as demais determinações da estrutura de reflexão - a saber, diferença, oposição, contradição e fundamento - são reunidas em uma única categoria identitária toda vez que a mesma se constitui, o que acaba por suspender, não apenas a contradição, como também todas as demais categorias, que agora têm a sua unidade na identidade.

Neste ponto, porém, poderia objetar-se que a identidade lógica é um princípio da lógica formal, e não da dialética hegeliana. Certamente, até mesmo porque, conforme explica Mctaggart, "no Ser a antítese de cada tese é o seu oposto direto"33, ao passo que, na lógica da essência "a diferença não é tão diretamente oposta à identidade, como o nada ao ser. (...). Como veremos a diferença é adicionada à Identidade e não a substitui" ${ }^{34}$.

\footnotetext{
32 "Der Grund und Boden der Wissenschaft, oder das Wissen im allgemeinen ist". (KULENKAMPFF, 1970, p. 101).

33 "in Being the Antithesis of each Thesis is its direct opposite". (MCTAGGART, 1910, p. 104).

34 "Difference is not so directly opposed to Identity, as Nothing is to Being. As we shall see, the Difference is added to the Identity, and 190 • Ágora Filosófica, Recife, v. 21, n. 1, p. 170-197, jan./abr., 2021
} 
Portanto, não é possível que a primeira categoria das determinações de reflexão seja, estritamente falando, a identidade lógica, onde o ser é imediatamente igual a ele mesmo.

Além disso, caso se queira discutir a origem destes princípios mais fundamentais, o princípio da identidade foi formulado por Parmênides há cerca de 2.500 anos. Entretanto, de certo modo, é no resultado postulado por Parmênides que Hegel chega ao final do desenvolvimento dialético das determinações de reflexão, ao afirmar que "tudo é igual a si mesmo"35. A diferença é que, em Hegel, na categoria da identidade não é o ser que é simplesmente igual ao ser (ou não apenas isso), mas é a negação que é igual a si mesma. É o não-ser que, justamente porque não é, torna-se idêntico a si mesmo.

É exatamente porque, na lógica da essência a diferença é adicionada, e não substitui a identidade que, em seu retorno, Hegel chega a esta conclusão. De acordo com Mactaggart, "superfície e substrato refletem um ao outro perfeitamente. Se partirmos de um A imediatamente dado e nos esforçarmos para compreendê-lo determinando a sua Essência, o resultado a que chegamos será "A é $A^{\prime \prime 36}$. A superfície, enquanto aparente, é a identidade da qual se parte, ao passo que o substrato é a essência que, ao ser revelada, mostra-se idêntica à sua identidade.

Pode-se dizer que a dialética desenvolvida por

does not replace" (MCTAGGART, 1910, p. 104).

35 "Alles ist sich selbst gleich". (HEGEL, 1969, p. 27).

36 "Surface and Substratum reflect each other perfectly. If we start from na immediately given $A$ and endeavour to understand it by determining its Essence, the result which we get at this point will be" $A$ is $A^{\prime \prime}$. (MCTAGGART, 1910, p. 103).

Ágora Filosófica, Recife, v. 21, n. 1, p. 170-197, jan./abr., $2021 \cdot 191$ 
Hegel na lógica da essência é uma investigação acerca da validade do princípio da identidade lógica, posto que a pergunta que norteia o método hegeliano (uma vez que, conforme já mencionado, Hegel parte de uma crítica a Kant) é se o ser é, ou não, idêntico a si mesmo. Dessa forma, Hegel parte, não da certeza, mas da pressuposição da identidade lógica. No decorrer de sua dialética, no entanto, percebe que a diferença, mesmo progredindo para oposição e contradição, acaba sempre por ser suprassumida, o que resulta na restauração, ou melhor, no retorno para a identidade inicial. Assim, na identidade lógica "(...) afirmamos que sua natureza tem os dois lados da superfície e do substrato, e que o conteúdo desses dois lados é o mesmo"37.

Hegel chega a essa conclusão por meio de seu método dialético. Entretanto, há que se ressaltar que Hegel não parte de um princípio lógico, pelo contrário, sua lógica é sem pressuposições e/ou princípios porque compreende o princípio da identidade lógica como uma tautologia. "No sentido em que afirma que $A$ é $A$, a proposição é uma completa tautologia. Sua verdade repousa não na identidade na diferença, mas na ausência de toda diferença" ${ }^{\prime 3}$. Uma tautologia é uma redundância lógica, no sentido de que afirma o ser de algo que já está sendo, é sob essa perspectiva que a identidade lógica é uma tautologia. E é também nesse sentido que Hegel vai questionar se, de fato, se pode partir do pressuposto de

\footnotetext{
37 "(...) we assert that its nature has the two sides of Surface and Substratum, and that the content of these two sides is the same". (MCTAGGART, 1910, p. 105).

38 "In the sense in which that asserts $A$ to be $A$, the proposition is a complete tautology. Its truth rests, not on identity in difference, but on the absence of all difference". (MCTAGGART, 1910, p. 105).
}

192 • Ágora Filosófica, Recife, v. 21, n. 1, p. 170-197, jan./abr., 2021 
que o ser é idêntico a si mesmo, uma vez que, na formulação dessa sentença, já entra em jogo tanto a categoria da identidade, quanto da diferença.

A diferença é uma antinomia presente no cerne desta operação, uma vez que o seu resultado é derivado do sendo (Seiendes) o que, em termos hegelianos, significa que se está sendo por meio de algo outro. E, conforme argumenta Kesselring, "as antinomias, uma vez descobertas, causam crises sistêmicas e exigem uma expansão do quadro conceitual em que elas ocorrem" (KESSELRING, 1984, p. 109), que é exatamente o que Hegel faz ao demonstrar, por meio de seu método dialético, que, desde sempre, é preciso usar as determinações da reflexão quando se tem que emitir um enunciado.

Todavia, Hegel não pretende, com isso, refutar os princípios mais fundamentais da lógica como o princípio da identidade e o princípio da não-contradição. Pelo contrário, a dialética hegeliana reafirma a validade lógica destes conceitos, tanto é que, através do movimento de suprassunção (Aufhebung) da contradição, Hegel retorna à identidade lógica, onde a diferença completa (oposição, portanto) encontra-se superada e, consequentemente, todas as demais determinações de reflexão. Disso se infere que o princípio da identidade, na lógica do ser, é sim ser igual a ser. Porém, na lógica da essência, o princípio da identidade é, também, mais do que isso, posto que a identidade estabelecida através da suprassunção da contradição carrega consigo uma negatividade que é imanente.

De acordo com Hegel "como o princípio de razão suficiente expressa: tudo o que é tem um fundamento, ou é postulado, mediado; assim também um princípio da existência teria que ser estabelecido e expresso como:

Ágora Filosófica, Recife, v. 21, n. 1, p. 170-197, jan./abr., 2021 • 193 
tudo o que é, existe" ${ }^{\prime 39}$. Na verdade, essa passagem expressa um dos principais problemas entre a lógica e a metafísica tradicionais, qual seja: se para a lógica formal tudo que se dá, se dá a partir do ser - o ser e seus atributos, conforme postulado por Aristóteles -, a metafísica, como seu próprio nome diz, se ocupa daquilo que está além do ser enquanto algo físico e/ou postulado.

Ao considerar que tudo possui um fundamento na medida em que, ou vem a ser por meio de uma determinação, ou provém de um momento ou estado anterior, ao mesmo tempo em que tudo o que existe já está, portanto, existindo, Hegel busca juntar as duas visões em seu método dialético, do que resulta um tipo de metalógica. Nessa metalógica, ao mesmo tempo em que o fundamento representa a série de progressões categoriais que levam à identidade do ser $=$ ser, por outro lado, o próprio fundamento já veio a ser por meio desta progressão, denominada por Hegel de determinações de reflexão, as quais se dão, primeiramente, de modo subjacente no âmbito do pensamento lógico.

Dessa forma, de acordo com Hegel, “(...) se o que é dito tiver um fundamento e for condicionado, também deve ser dito que não há fundamento para isso e é incondicionado. Pois a Existência é a imediatez que surge da superação da mediação referente ao fundamento e à condição"40. Ou seja, para Hegel o imediato, ou melhor, a

39 "Wie der Satz des Grundes ausdrückt: Alles was ist, hat einen Grund, oder ist ein Gesetztes, ein Vermitteltes; so müßte auch ein Satz der Existenz aufgestellt und so ausgedrückt werden: Alles, was ist, existirt". (HEGEL, 1999, p. 324).

40 “(...) auch gesagt wurde, was existirt, hat einen Grund und ist bedingt, so müßte auch eben so gesagt werden: es hat keinen Grund und ist undedingt. Denn die Existenz ist die aus dem Aufheben der 194 • Ágora Filosófica, Recife, v. 21, n. 1, p. 170-197, jan./abr., 2021 
identidade lógica imediata é o resultado da superação do fundamento enquanto condição para que algo venha a ser, e a introdução da categoria existência, nessa sequência, reforça essa progressão, no sentido de que algo vem a ser - se torna existente, portanto - justamente ao efetivar este movimento.

Assim, a próxima progressão categorial, qual seja, do fundamento à existência, refere-se a este movimento de superação de si mesmo que, consequentemente, força o retorno do fundamento à identidade lógica, onde o mesmo vem a ser justamente por meio daquilo que não é. Formalmente, o fundamento determinado é apenas identidade lógica, porém, sob a perspectiva de Hegel, a determinação do fundamento significa que o mesmo veio a ser - passou a existir, portanto - a partir de um movimento de suprassunção gradativa das categorias diferença, oposição e contradição que, todavia, desvanecem na identidade lógica. A dissolução destas categorias ulteriores revela que a antinomia já se encontra presente na primeira categoria, a da identidade. Porém, o que Hegel faz, por meio da estrutura das determinações de reflexão, é demonstrar, passo a passo, como ocorre o movimento de conversão de uma categoria em sua categoria oposta, e como este movimento forma a unidade identitária.

\section{Referências}

ARISTÓTELES. Metafísica. São Paulo: Edipro, 2006.

HEGEL, G.W.F. Enciclopédia das ciências filosóficas. A ciência da lógica. 3. ed. São Paulo: Loyola, 2012.

durch Grund und Bedingung beziehenden Vermittlung hervorgegangene Unmittelbarkeit". (HEGEL, 1999, p. 324). 
HEGEL, G.W.F. Encyclopedia Das Sciencias Philosophicas Em Compendio. I Logica. São Paulo: Impressora Commercial, 1936.

HEGEL, G.W.F. Ciência da Lógica. Excertos. São Paulo: Barcarolla, 2011.

HEGEL, G.W.F. Ciência da Lógica. A Doutrina do Ser. Rio de Janeiro: Vozes, 2017.

HEGEL, G.W.F. Wissenschaft der Logik. Die objektive Logik. Zweites Buch: Die Lehre vom Wesen. Hamburg: Felix Meiner Verlag, 1969.

HEGEL, G.W.F. Ciência da Lógica. A Doutrina da Essência. Rio de Janeiro: Vozes, 2017.

HEGEL, G.W.F. Ciência de la lógica. Buenos Aires: Solar S.A/Hachette S.A, 2. ed., 1968. Traducción directa del alemán de Augusta y Rodolfo Mondolfo.

HEGEL, G.W.F. Wissenschaft der Logik; Die objektive Logik; Die Lehre vom Sein (1832); Die Lehre vom Wesen (1813). Hamburg: Felix Meiner Verlag, 1999.

HORSTMANN, R.P. La contradicción en Hegel. Argentina: Revista Latinoamericana de Filosofia. Volume: XXXV, $N^{\circ} 2$, 2009.

KANT, Immanuel. Crítica à razão pura. São Paulo: Acrópolis, 2008.

HEGEL, G.W.F. Kritik der reinen Vernunft. Hamburg: ed. J. Timmermann, Felix Meiner, 1988.

KESSELRING, Thomas. Die Produktivität der Antinomie. Hegels Diealektik im Lichte der genetischen Erkenntnistheorie und der formalen Logik. Frankfurt: Suhrkamp Verlag, 1984.

KULENKAMPFF, Arend. Antinomie und Dialektik. Zur Funktion des Widerspruchs in der Philosophie. Frankfurt: J.B Metzler, 1970. 
MCTAGGART, John e Ellis. A commentary on Hegel's Logic. Cambridge: The University Press, 1910.

ROSENFIELD, D.L. Deus e o Absoluto. Porto Alegre: Revista Veritas, vol. 63, (p. 33-51), 2018.

WANDSCHNEIDER, Dieter. Das problem der dialektik. Bonn: Bouvier Verlag, 1997.

WANDSCHNEIDER, Dieter. Spazio, tempo e relatività nella prospettiva della 'Filosofia della Natura' di Hegel. Napoli: Bibliópolis, 1984.

WÖLFLE, G.M. Die Wesenslogik in Hegels Wissenschaft der Logik. Versuch einer Rekonstruktion und Kritik unter besonderer Berücksichtigung der philosophischen Tradition. Stuttgart - Bad Cannstatt: frommann - holzboog, 1994.

Michele Borges Heldt

Doutora em Filosofia pela Universidade do Vale do Rio dos Sinos UNISINOS.

E-mail: heldt.michele@hotmail.com

Submetido: $19 / 05 / 2020$

Aprovado: 17/10/2020 